Displacement of the lower fragment of the radius$\begin{array}{lllllllllll}\text { Inwards } & \ldots & \ldots & \ldots & \ldots & \ldots & \ldots & \ldots & \ldots & \ldots & \ldots\end{array}$

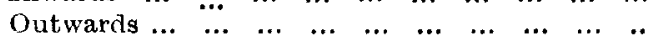

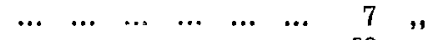
$\begin{array}{llllllllllrl}\text { Backwards } & \ldots & \ldots & \ldots & \ldots & \ldots & \ldots & \ldots & \ldots & \ldots & 60 & , \\ \text { Outwards and forwards } & \ldots & \ldots & \ldots & \ldots & \ldots & \ldots & 2 & \text {," }\end{array}$

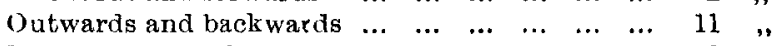

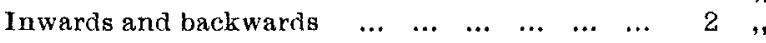
$\begin{array}{llllllll}\text { Impaction without comminution } & \ldots & \ldots & \ldots & \ldots & \ldots & 67 & \text {, }\end{array}$

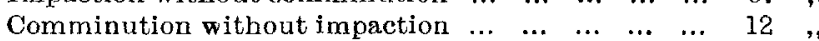
Impaction and comminution

separation of the epiphysis is counted as a transverse fracture and also that damage to the styloid prucess of the ulna is not counted as a fracture of that bone. Of the total number, 155 consisted of fractures of the radius only, but two cases occurring in which the ulna was alone fractured. In seven cases both bones were fractured, while in one other the only injury that could be detected was a fracture of the trapezium. No fracture could be detected in five cases in one of these there was some lipping of the carpal border of the radius due to ostenarthritis. Separation of one or both epiphyses occurred in 11 of the cases and three were complicated with a dislocation of the wrist-joint. The styloid process of the radius was cracked off in 20 cases, and this injury accounts for practically all those where the line of tracture was oblique, as well as for some of those which are described as "transverse but line irregular." Further, in all of these 20 cases the line of fracture ran into the joint. The wrist-joint was involved in 25 cases. This number includes the 20 cases above referred to and also some where the line of fracture was "irregular" or where there was comminution of the lower fragment. The frequency with which the styloid process of the ulna is torn off wholly or in part is very remarkable, occurring as it coes in more than half the total number of cases. If we take those cases where the radius only was fractured to constitute "Colles's fracture" this process is damaged more or less in 85 of the 155 cases, or 55 per cent. This percentage, however, will be found too low for injuries which are strictly "Colles's fractures," since amongst the 155 cases are included several of the styloid process of the radius and others which are not true "Colles's fractures."

Part 2 of Table I. refers to the lower end of the radius. Oat of the 162 cases in which this bone was broken the line of fracture was transverse or approximately at right angles to the line of the shaft in 120 , or 74 per cent. In all of those where the line of fracture was oblique, the line ran across the base of the styloid process and communicated with the joint. In those described as "irregular" there was considerable smashing of the end of the bone with no definite line in any particular direction. In two of those described as "obliquely transverse" the line of fracture lay across the bone otliquely without involving the joint. Among those where the fracture was "transverse but line irregular" were several in which the line was more or less curved with the convexity of the curve looking downwards. The average distance of the line of fracture from the carpal border was measured in all cases-those where the line was oblique and leading into the joint not being included in the table of measurements. The rapid rise in numbers from two at one-eighth of an inch to 62 at half an inch is very interesting, as is also the more rapid fall after this point is pissed. It will be seen that in no less than 111 out of a total of 155 cases the line of fracture is half an inch or less from the carpal border, just over 71 per cent., while in 31 only is the distance over half an inch -20 per cent.

In Erichsen's "Surgery," tenth edition, 1895, p. 598, it is said: "Gordon, who gave great attention to the mechanism of this fracture, states that in 27 old specimens examined by him the line of fracture post riorly varied from $\frac{3}{5}$ inch to $1 \frac{3}{4}$ inch, and anteriorly from 3 inch to 2 inches above the carpal border of the radius, being in ten 1 inch and under, in ten more than $1 \mathrm{inch}$, and in the others indefinable." It is interesting to compare these statements with the present series of fractures near the wrist where, out of a total of 155, in only two is the line of fracture over one inch above the carpal border.

The state of the lower fragment was a fertile source of discussion in the pre-Roentyen ray days. In the present series it will be seen that as regards displacement this takes place in a backward direction more than twice as often as all the other àisplacements taken together. In a large number of the cases there was no material displacement shown in the radiograph and in many of these there was impaction of

the upper into the lower fragment. Impaction was present in 88 cases-nearly 57 per cent.-21 of these being accompanied with comminution-comminution without impaction occurring in 12. Displacement upwards has not been recorded in this series. A certain amount always takes place when the lower fragment is displaced and tilted backwards, and also there is, of course, some shortening with impaction of the upper into the lower fragment. In none of the cases was there displacement upwards, such as occurs in a case of fracture of the middle of the shaft of the femur.

It will be remembered that in all the 170 cases such history and signs as could be elicited gave reasonable supposition of the existence of "Colles's fracture," and Table I. is valuable in showing what conditions may simulate this injury at times. Several of the cases are, of course, not "Colles's fractures," and in Table II. an attempt has been

TABLE II.

An Analysis of Radiograplic Negatives Ireparcd from 150 Cases of

The line of fracture-

$\begin{array}{lllllllllll}\text { Transverse } & \ldots & \ldots & \ldots & \ldots & \ldots & \ldots & \ldots & \ldots & \ldots & 110 \text { cases. }\end{array}$

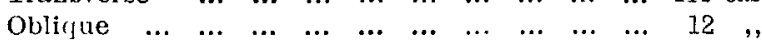

Irregular

Obliquely transverse

Transverse but line irregul

The distance from the carpal border-
$?$ inch
$\frac{1}{4}$, ,
2 cases.
$\begin{array}{llll}, & \ldots & 14 & \\ , & \ldots & 29 & ,\end{array}$
" $\quad \cdots 61$

Displacement of the lower fragment-

Inwards

Forwards

Backwards

Outwards and forwards $\ldots$

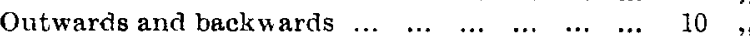

Inwards and backwards

Impaction without comminution

Comminution without impaction

Comminution and impaction

Dislocation of the wist complicating fracture...

Fracture of the styloid process of the radius $\quad \ldots \quad$...

Fracture communicating with the wrist-joint ...

Fracture of the styloid process of the ulna ...

made to prepare an analysis based only on such of the cases as conform to this injury. For this purpose only those where there was fracture of the lower end of the radius alone were taken, ignoring among others fracture of both bones and also separation of one or both epiphyses which leaves a total of 150 cases. This includes 11 cases where the line of fracture ran across the base of the styloid process of the radius communicating with the joint and having no displacement worth noting, certainly none that could have been detected clinically. This number can be deducted from the total and also from the figures relating to the styloid process of the radius and those of the fractures communicating with the wrist-joint if it is felt that they should not be included when calculating percentages, but it must be remembered that they were "Colles's fractures" from the clinical point of view.

My best thanks are due to the receiving-room officers and to the assistants in the electrical department for their kind assistance in collecting these cases.

Queen Anne-street, W.

\section{NOTE ON THE USE OF ACETO-SALICYLIC ACID IN RHEUMATIC ENDO- PERICARDITIS.}

BY EDWARD C. B. IBOTSON, M.B. LOND,

THE patient whose case is now described was in the third week of her third attack of rheumatic fever when $I$ was called to her on Nov. 3rd, 1906. She was nearly 16 years of age, thin and anæmic, with very dark hair and irides. There was no family history of rheumatism. The joints were not much affected. Loud pericardial friction sounds with well-marked to-and-fro bruit masking an endocardial presystolic bruit were heard. There were well-marked dulness and tubulas breathing below the left scapula 
and rhonchi in the right chest posteriorly. The pulse and respiration were rapid. The urine was scanty, high-coloured, but non-albuminous. Constipation and obstinate insomnia were present. There was great tenderness of the spine and especially of the cervical spine. There were incipient bedsores over the sacrum. I ordered farinaceous diet. A bed-rest was provided and oxide of zinc powder was used for the sacral region. A cantharides plaster, measuring two inches by two inches, was applied over the second left intercostal space. A two grains of calomel was taken at bed-time and a mixture containing sodium salicylate and potassium iodide was given three times a day. The temperature, pulse-rate, and respirations recorded at 1 P.M. from Nov. 1st to the 6th were respectively as follows : on Nov. 1st, $102^{\circ}$ F., 120, and 40 ; on the $2 \mathrm{nd}, 101^{\circ}, 120$, and 40 ; on the $3 \mathrm{rd}, 100^{\circ}, 120$, and 32 ; on the $4 \mathrm{th}, 100 \cdot 4^{\circ}, 120$, and 36 ; and on the $5 \mathrm{tb}$, $101^{\circ}, 120$, and 40 . On the 6 th the temperature was $100^{\circ}$. On the 7th it was $101^{\circ}$ and the pulse rate was 130 ; at 9 P.M. 15 grains of aceto-salicylic acid were given which produced a profuse perspiration during the night. On the 8th the temperature was $98^{\circ}$ and the pulse-rate was 112 ; the blisters and the Dover's powder were continued for the relief of the insomnia and cardiac distress. On the 10th the temperature again rose to $101^{\circ}$ and 15 grains of aceto-salicylic acid were given at night. On the 12th the temperature dropped to normal and did not again rise. Aceto-salicylic acid in doses of seven grains three times a day was continued till Nov. 19th and iodine paint was applied over the posterior chest. The friction sounds, the dulness, and the pulmonary congestion gradually disappeared. On Nov. 20th a mixture containing 10 grains of bremoglobin, two minims of liquor strychninæ, and 10 minims of tincture of strophanthus was given three times a day and this was continued for some weeks, when she was attacked by inflammation of the posterior cervical glands which caused temporary wryneck. Hot fomentations and iodide of iron subdued this complication. At the present time (Febraary, 1907) the anæmia has almost gone, the patient is able to get about, and the only trace of her illness is a loud presystolic murmur, indicating well-compensated mitral constriction.

The case seems to point to the superiority of aceto-salicylic acid in rheumatic fever, in certain cases when a salicylate has had a good trial, but the value of the blisters and opium must not be overlooked. Moreover, the hæmoglobin appears to be less likely to produce relapse than iron salts in combating the subsequent anæmia. I have had evidence also of the superiority of aceto-salicylic acid since then in (1) a stout woman, aged 41 years ; (2) a man, aged 35 years; and (3) a boy, aged nine years. all of whom failed to respond to a salicylate. I have found a salicylate aggravate epistaxis which in my experience is not by any means an uncommon concomitant of rheumatism and is probably due to the accompanying anæmia. It is important that the acetosalicylic acid should not be given in tabloid form unless the tabloids are crushed before administration. The powder suspended in water with a little mucilage acts well and has no anpleasant taste.

I have not found aceto-salicylic acid produce headache or dyspepsia, but I think that it is contra-indicated in chronic rheumatism occurring in the subjects of organic heart disease of non-rhenmatic origin. The "Medical Annual" for 1904 quotes Georges (Berliner Klinische Wochenschrift) as pointing out that aceto-salicylic acid is of value in all forms of rheumatism, whether in the joints, the heart, or the muscles ; and in chorea. As regards price, it is now sold at $4 d$. per ounce, or $4 s$. per pound, whereas physiologically pure sodium salicylate is $3 s$. per pound, so the difference in price is not prohibitive.

Great Dover-street, S.E.

The Royal Institution Lectures.-Among the lectures to be delivered at the Royal Institution after Easter are the following: Malaria, Sleeping Sickness, Tick Fever, and Allied Diseases, by Professor G. H. F. Nuttall ; Spectroscopic Phenomena in Stars, by Mr. H. F Newall; Chemical Progress (Mendeléeff and Moissan), by Professor Sir James Dewar; Studies in Magnetism, by Professor S. P. Thompson; and Scientific Work in the Sea Fisheries, by Professor W. C. McIntosh. Lectures will also probably be given by Sir James Crichton-Browne and Professor J. A. Fleming.

\section{Shledital Socteties.}

\section{ROYAL MEDICAL AND CHIRURGICAL SOCIETY.}

Observations on a Case of Chyluria Ocourring in England, with a Report of the Post-mortem Examination.

A MEETING of this society was held on March 12th, Mr. J. WARRINGTON HAWARD, the President, being in the chair. Dr. ARThUR F. HeR'] z read a paper on Observations on a Case of Chyluria occurring in England, with a Report of the Post-mortem Examination. He said that the patient was a sailor, aged 66 years. When admitted into Gup's Hospital, under the care of Dr. G. Newton Pitt, in October, 1906, he had been passing milky urine for nine months. In that period he had lost nearly two stones in weight and had been occasionally troubled with difficulty in micturition due to intravesical clotting of his urine. The patient was in India for a short time 20 years before the onset of the disease. In eight of the 33 collected cases of chpluria of supposed European origin the patients had been in some tropical country many years earlier, and only 17 were specifically stated never to have been in the tropics. This suggested that some of the cases of supposed European origin were due to an old filarial infection, but no filariæ could be found in the blood or urine of this patient. The fat in the chylous urine was present in "molecular" condition, similar to the condition in which fat was found in chyle, Leucocytes were invariably present, but no red corpuscles or casts were found. Fibrin shreds were always present, but during the period of observation the urine never clotted into a gelatinous mass, as it had done before the patient's admission into hospital. No creamy layer formed on standing or after centrifugalisation. On warming a membrane formed on the surface similar to the "skin" of heated milk. The opacity of the urine was due entirely to the presence of fat which dissolved in ether after addition of sodium carbonate. Protein was invariably present in the chylous urine but dextrose was never found. The chylous condition of the urine disappeared spontaneously for a week during October; no cause could be discovered either for the disappearance or the reappearance. A second disappearance of the chyluria occurred immediately after a cystoscopic examination, which was made eight days before death, and the chyluria did not return. A diet as free as possible from fat resulted in the complete disappearance of fat and protein from the urine if the patient rested after meals. Excess of protein or carbohydrate had no effect at all on the urine. Fat in the food gave rise to chyluria. The first trace of fat and protein in the urine occurred as early as 33 minutes after the fat had been eaten. With a full diet the maximum amount of fat appeared in the urine five hours after the meal and the last traces disappeared in eight hours. The exact variations produced in the urine by changes in diet were studied by comparing hourly specimens of urine, and photographs of two series of specimens showing the influence of diet were taken. It appeared probable that the fat in the urine came directly from that in the food and not from the stores of fat in the body. For the first time the influence of exercise on chyluria was clearly shown. Chylous urine appeared sooner after a meal and more fat was present if exercise was taken than if the meal was followed by rest. If a fat-free diet was given and exercise was taken "lymphuria" resulted; serum-albumin, serumglobulin, fibrinogen and fibrin flakes, and leucocytes were present in the urine with no trace of fat. Movements of either leg, but not of either arm, gave rise to this lymphuria. Chyluria and lymphuria were both increased by the assumption of the vertical position. As to the necropsy, the thoracic duct was found to be impermeable at a point seven centimetres above the diaphragm. The abdominal lymphatics were much dilated and a well-marked anastomosis was traced between the lacteals and the lymphatics on the right side of the bladder. Mercury could be injected at low pressure in a direction contrary to the normal flow from the upper abdominal lymphatics to the bladder. Iuside the bladder, at a point exactly corresponding to the dilated lymphatics, was found a minute papilliform mass of fibrin, closely adherent to the mucous membrane. There seemed little doubt that this marked the position where chyle from the intestinal lacteals and lymph 